\title{
Gata2 Is Required for Migration and Differentiation of Retinorecipient Neurons in the Superior Colliculus
}

\author{
Ryan T. Willett ${ }^{1,2}$ and Lloyd A. Greene ${ }^{2}$ \\ Departments of ${ }^{1}$ Pharmacology and ${ }^{2}$ Pathology and Cell Biology, Columbia University College of Physicians and Surgeons, New York, New York 10032
}

The superior colliculus (SC)/optic tectum of the dorsal mesencephalon plays a major role in responses to visual input, yet regulation of neuronal differentiation within this layered structure is only partially understood. Here, we show that the zinc finger transcription factor Gata2 is required for normal SC development. Starting at embryonic day 15 (E15) (corresponding to the times at which neurons of the outer and intermediate layers of the SC are generated), Gata2 is transiently expressed in the rat embryonic dorsal mesencephalon within a restricted region between proliferating cells of the ventricular zone and the deepest neuronal layers of the developing SC. The Gata2positive cells are postmitotic and lack markers of differentiated neurons, but express markers for immature neuronal precursors including Ascl1 and Pax3/7. In utero electroporation with Gata2 small hairpin RNAs at E16 into cells along the dorsal mesencephalic ventricle interferes with their normal migration into the SC and maintains them in a state characterized by retention of Pax 3 expression and the absence of mature neuronal markers. Collectively, these findings indicate that Gata2 plays a required role in the transition of postmitotic neuronal precursor cells of the retinorecipient layers of the SC into mature neurons and that loss of Gata2 arrests them at an intermediate stage of differentiation.

\section{Introduction}

The superior colliculus (SC)/tectum is a laminar midbrain structure involved in head and eye orientation to sensory stimuli. Retinal ganglion neurons project to the upper layers of the SC and synapse onto retinorecipient neurons to form a topographic map representing the visual field (O'Leary and McLaughlin, 2005). Deeper layer SC neurons receive inputs from cortex and basal ganglia and project radial processes into the retinorecipient laminae. During embryonic development, the laminar SC structure is constructed by sequential cohorts of cells that are generated in the ventricular zone and that migrate dorsally toward the pial surface. In chick embryo, deep layer tectal neurons are generated first, a second wave produces the outermost retinorecipient layers, and a third and final wave generates the interstitial lamina (Gray and Sanes, 1991; Sugiyama and Nakamura, 2003). Although there is much progress in understanding the mechanisms underlying retinotectal mapping, only partial information exists about regulation of neuron differentiation in the SC.

The GATA transcription factor family binds the DNA sequence WGATAR and, along with other cofactors, drives expression of target genes important in development of a variety of tissues. GATA members present in the nervous systems include Gata2 and Gata3 (Groves et al., 1995; Tsarovina et al., 2004). As in hematopoiesis, Gata3 appears after Gata2 and operates downstream in most cases evaluated (Groves et al., 1995; Kala et al.,

Received Sept. 1, 2010; revised Sept. 24, 2010; accepted Jan. 16, 2011.

This work was supported in part by National Institutes of Health-National Institute of Neurological Disorders and Stroke Grants T32 GM007182, NS33689, and P50 NS038370. We thank Drs. Jin-Wu Tsai and Richard Vallee for aid with in utero electroporation.

Correspondence should be addressed to Lloyd A. Greene at the above address. E-mail: lag3@columbia.edu. DOI:10.1523/JNEUROSCI.4616-10.2011

Copyright $\odot 2011$ the authors $\quad 0270-6474 / 11 / 314444-12 \$ 15.00 / 0$
2009). Gata2 is expressed in embryonic dorsal diencephalon, ventral hindbrain including serotonergic neurons, V2 spinal cord interneurons, autonomic neurons, and cell types throughout the mesencephalon (Kornhauser et al., 1994; Groves et al., 1995; Bell et al., 1999; Zhou et al., 2000; Craven et al., 2004; Kala et al., 2009). Gata2-null mice exhibit a profound failure of hematopoietic stem cell differentiation (Tsai et al., 1994), as well as neurodevelopmental defects including abnormal axon pathfinding, fasciculation, and arborization (Nardelli et al., 1999). Although early lethality of Gata2-null mice [embryonic day 10.5 (E10.5)] precludes their use for studying the role of Gata2 in differentiation of later born neurons, various studies show that Gata2 is required for V2b spinal interneuron subtype identity (Zhou et al., 2000; Karunaratne et al., 2002), drives precocious neuronal differentiation in chick spinal cord (El Wakil et al., 2006), and is sufficient for ectopic serotonergic neuron specification in lateral hindbrain (Craven et al., 2004). Additionally, regionspecific knock-out indicates that Gata2 is necessary for GABAergic phenotype of early-born interneurons in the inferior colliculus (IC) (Kala et al., 2009). Detection of Gata2 in dorsal midbrain was first reported in chick optic tectum, where its laminar expression and spatiotemporal regulation during embryogenesis suggested a function in determining neuronal fates (Kornhauser et al., 1994).

Here, we address the role of Gata2 in development of the embryonic rat SC. Gata2 protein expression begins at E15 and is transiently present and restricted to a periventricular zone of immature postmitotic SC neuronal precursors. In utero electroporation of Gata2-targeted short hairpin RNAs (shRNAs) indicates that Gata2 is required for migration of this population to the outer layers of the SC and for their differentiation into mature neurons. Gata2-knockdown cells retain markers for immature 
neuronal precursor cells. These results place Gata2 as a critical fate determinant in late-phase SC neurogenesis.

\section{Materials and Methods}

Materials. Platinum TaqDNA polymerase, One Shot TOP10 competent bacteria, and Lipofectamine 2000 were from Invitrogen. Tri Reagent was from Molecular Research Center. SuperBlock Blocking Buffer was from Thermo Fisher Scientific. Human recombinant NGF was a kind gift from Genentech.

Antibodies. Antibodies used for immunohistology were as follows: rabbit anti-Gata2 (Santa Cruz Biotechnology; sc-9008 X; lot J2108), rabbit anti-Ki67 (Vector Laboratories), mouse anti-green fluorescent protein (GFP) (University of California, Davis/National Institutes of Health NeuroMab Facility), rabbit anti-GFP (Invitrogen), mouse anti-Ascl1 (BD Biosciences Pharmingen), rabbit anti-Msil mouse anti-neuronal nuclei (NeuN), rabbit anti-Sox2 mouse anti-tyrosine hydroxylase (TH), anti-GAD1 clone 1G10.2, guinea pig anti-DCX (all from Millipore Bioscience Research Reagents), mouse anti-NF-1 and mouse PH2A.X ( $\gamma$ H2A.X) (Abcam), mouse anti-phosphohistone H3 (Ser10) and cleaved caspase 3 (Cell Signaling Technology), ERK 1 (Santa Cruz Biotechnology), and rabbit anti-peripherin (Aletta et al., 1988).

Pax3, Pax7, Nkx2.2, and Nkx6.2 antibodies, developed by C. P. Ordahl (University of California, San Francisco, San Francisco, CA), A. Kawakami (Tokyo Institute of Technology, Tokyo, Japan), T. M. Jessell (Columbia University, New York, NY), and O. D. Madsen (Hagedorn Research Institute, Gentofte, Denmark), respectively, were obtained from the Developmental Studies Hybridoma Bank developed under the auspices of the National Institute of Child Health and Human Development and maintained by Department of Biology, University of Iowa (Iowa City, IA).

Plasmids. Plasmid pCR2.1-TOPO was from Invitrogen; pCMS-EGFP and pSIREN-RetroQ-zsGreen were from Clontech; and pcDNA-GATA2 vector was from Addgene [plasmid 1287, from Gokhan S. Hotamisligil, Harvard University, Boston, MA (Tong et al., 2000)].

Overexpression and short interfering RNA (siRNA) knockdown constructs were derived from plasmids pCMS-EGFP and pSIREN-RetroQZsGreen (Clontech). Targeting sequences for siRNA cassettes were designed using the design tool available on the BaRC website (Whitehead Institute, Massachusetts Institute of Technology, Cambridge, MA). Inactivation of siGATA2-1 to generate siRNA control (siCon) was achieved by substituting positions $2-6$ of the sequence with the reverse complement. These sequences were designed into a hairpin expression cassette and cloned into pSIREN-RetroQ-ZsGreen, and this U6-siRNA promoter/ knockdown cassette was subcloned into pCMS-EGFP in place of CMVMCS with the restriction enzymes BgIII and EcoRI. The siRNA targeting sequences were as follows: siCon, GCACCTGATGTCTTCTTCAACC; siGata2-1, GAGGTGGATGTCTTCTTCAACCA; siGata2-2, GGACGAGGTGGATGTCTTCTTCAA.

Cell culture. Culture and transfection of PC12 cells (Greene and Tischler, 1976) are detailed in the study by Xu et al. (2001). Generation of stable, retrovirally transduced PC12 lines was as reported by Cunningham et al. (2001).

Immunohistology. Developmentally timed Sprague Dawley rat embryos were drop fixed in $4 \%$ paraformaldehyde in PBS $(1 \times$ PBS $)$ for $2 \mathrm{~d}$. They were then cryoprotected in $30 \%$ sucrose $/ 1 \times$ PBS and coronally sectioned at $14 \mu \mathrm{m}$ for developmental expression studies or $50 \mu \mathrm{m}$ for electroporated brain samples. Sections were blocked in SuperBlock with $0.3 \%$ Triton $\mathrm{X}-100$ for $1 \mathrm{~h}$ and primary antibodies were bound overnight at $4^{\circ} \mathrm{C}$. The sections were washed three times for 15 min each time with $1 \times$ PBS $(0.3 \%$ Triton X-100) and Alexa Fluor-conjugated secondary antibodies were bound for $1 \mathrm{~h}$ before three more washes.

In utero electroporation. In utero electroporation was as described by Biswas et al. (2010) except that DNA $(2 \mu \mathrm{g} / 1 \mu \mathrm{l})$ was injected through the dorsal mesencephalon rather than telencephalon. Because of the thin lateral dimension of the mesencephalic ventricle, the capillary syringe was placed through the dorsal midline angled in the direction of the cephalic flexure. Injection into the ventricle was verified by Fast Green in the DNA solution. Brains were dissected and drop fixed in $4 \%$ paraformaldehyde/PBS. For migration and marker studies, embryos were electroporated at E16 and killed at E21 or postnatal day 5 (P5). For cell death
A
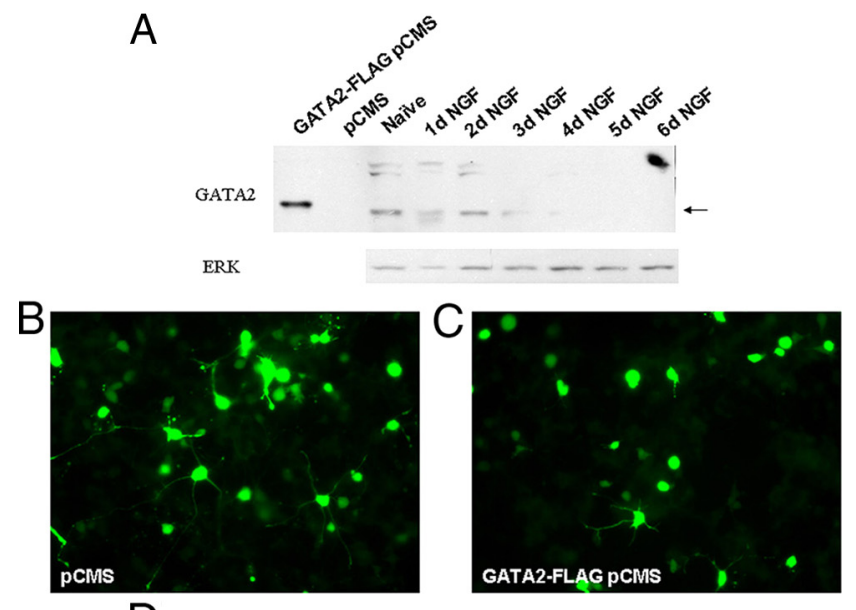

$\mathrm{D}$
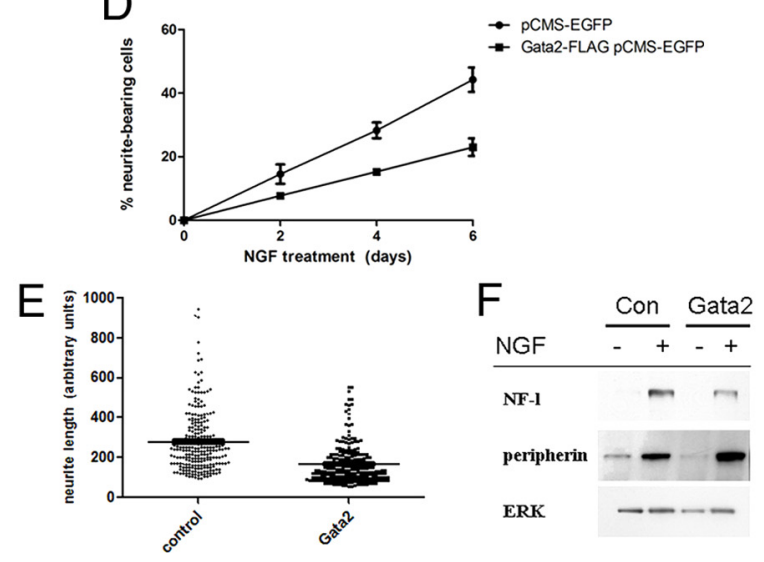

Figure 1. Gata2 is a NGF-responsive gene and suppresses neurite outgrowth in PC12 cells. $A$, NGF diminishes expression of Gata2 protein. PC12 cells were exposed to NGF over $6 \mathrm{~d}$, and Western immunoblots of protein lysates were performed using anti-Gata2. Lysates from Gata2 pCMS-EGFP transfected HEK293 cells were used as a positive control. B-D, Constitutive overexpression of Gata2 suppresses NGF-promoted neurite outgrowth. Cells were transfected with $G$ Gata2 vector and $1 \mathrm{~d}$ later treated with NGF. Cells in $\boldsymbol{B}$ and $\boldsymbol{C}$ were expose to NGF for $8 \mathrm{~d}$. Values in $\boldsymbol{D}$ represent average counts of percentage of transfected cells with neurites in triplicate replicate cultures $\pm \mathrm{SEM}$. Similar results were achieved in five independent experiments. $\boldsymbol{E}$, Gata2 overexpression reduces the lengths of NGF-induced neurites in polyclonal PC12-derived cells constitutively expressing Gata2. Gata2 and control vectors were introduced by infection with PQNCX retrovirus. Cells were exposed to NGF for $8 \mathrm{~d}$. Points represent result of individual measurements $(n=240-270)$ of neurite lengths in arbitrary units. The horizontal lines represent mean neurite lengths. $\boldsymbol{F}$, Gata2 overexpression does not blunt the effect of NGF on induction of neurofilament light and peripherin proteins. Experiment was performed in polyclonal cell lines with or without stable expression of retrovirally introduced Gata2. NGF treatment was for $5 \mathrm{~d}$.

marker studies, embryos were electroporated at E16 and killed at E18. For in vivo knockdown verification, embryos were electroporated at E15 and killed at E17.

Western blot. Western blot was performed as previously described $(\mathrm{Xu}$ et al., 2001). The antibodies used are referenced above (see Antibodies).

Migration analysis. Overlapping fluorescent micrographs of specimens were photographed at $20 \times$ on a Nikon epifluorescent microscope, and then assembled into contiguous fields. The distance of each labeled cell body from the ventricular surface was measured with ImageJ and normalized to the entire ventricular zone (VZ)-pial thickness at that position ( $n=3$ brains/condition; three to four sections imaged/brain; $n=$ $100-300$ cells counted/section). Values were expressed as percentages of this thickness and assigned into bins for distance traversed (sector A, 0-30\%; sector B, 31-60\%; sector C, 61-100\%). Sections were selected for analysis if electroporated radial glia fibers could be followed for the majority of the SC thickness.

Electroporation marker analysis. Sections were imaged with the Velocity software suite on a hybrid spinning disk confocal microcope 
A
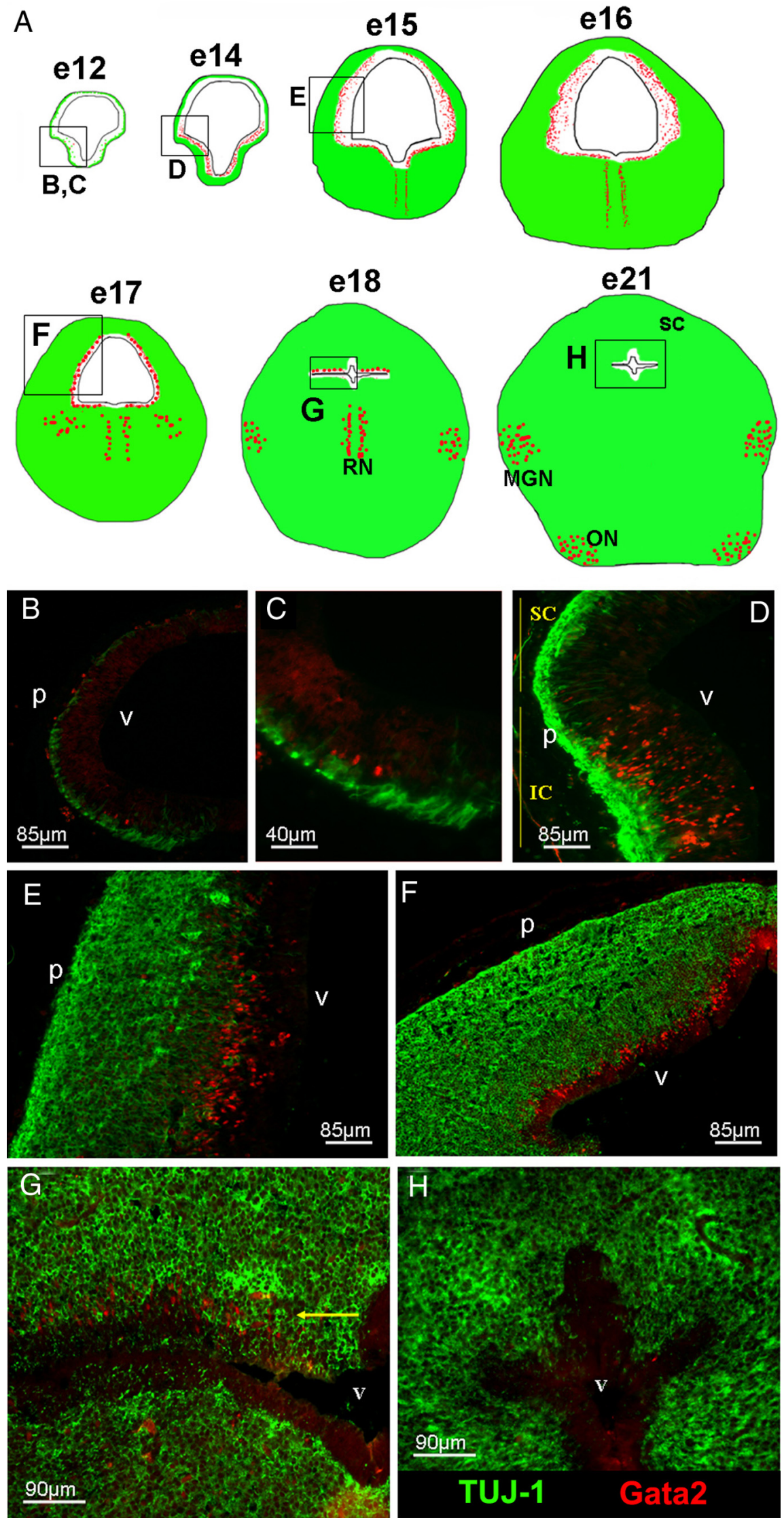

Figure 2. Dynamics of Gata2 expression during embryonic rat midbrain development. $A$, Depiction of Gata2 expression during various stages of rat embryonic midbrain development. Gata2 expression is in red, and TUJ1 expression in green. The boxes in diagrams show fields magnified in the images below $(\boldsymbol{B}-\boldsymbol{H}) \cdot \boldsymbol{B}(\mathrm{zoom}, \boldsymbol{C})$, The earliest Gata2-expressing cells appear in the ventrolateral
(PerkinElmer) using an ORCA-ER camera (Hamamatsu) at $60 \times$ with an argon ion laser (CVI Melles Griot). For each marker and each electroporated construct, three brains were analyzed with four sections from each for a total of 10-15 images/brain. Micrograph fields were assessed for ratio of electroporated/GFP + cells positive for immunostained markers. Approximately 3-15 electroporated cells typically appeared in each $60 \times$ field. Counts from the same brain were pooled, and counts of duplicate experiments were used for mean and SEM calculations.

\section{Results}

Gata2 is downregulated by NGF in

PC12 cells and influences their neuronal differentiation

Our interest in Gata2 arose from findings that NGF-promoted neuronal differentiation of PC12 pheochromocytoma cells is accompanied by loss of detectable Gata2 transcripts (Greene and Angelastro, 2008). Western immunoblotting confirmed that Gata2 protein levels are undetectable by $4 \mathrm{~d}$ of NGF exposure (Fig. 1A). To assess the role of Gata2 in this system, we overexpressed it either transiently or constitutively and monitored NGF-dependent neuronal differentiation. This reduced the rate of neurite production by twofold (Fig. $1 B-D$ ) and markedly decreased neurite length (Fig. $1 E)$. In contrast, constitutive Gata2 expression did not affect induction by NGF of peripherin or neurofilament light protein (Fig. $1 F)$. These findings are consistent with the general themes that Gata2 is regulated during neuronal differentiation and may play functionally important roles in this process.

GATA2 protein is transiently expressed and confined to a periventricular zone during mesencephalic embryonic development

To extend our studies to brain development, we used immunohistofluorescence staining of Gata2 protein. Consistent with previous work (Bell et al., 1999; Zhou et al., 2000; Craven et al., 2004; Herberth et al., 2005; Kala et al., 2009), we observed expression in embryonic rat hindbrain

midbrain at E12. D, By E14, expression is widespread in the IZ of the ventral mesencephalon. $\boldsymbol{E}, \boldsymbol{F}$, Expression of Gata2 extends to the dorsal mesencephalon where it persists from E15 to $E 17$ in the IZ directly beneath the neuronal layer. $\mathbf{G}$, Expression in zones of ongoing neurogenesis vanishes ventrally at E18, but remains in a layer (arrow) beneath and adjoining the neuronal $\mathrm{SC}$, before $\boldsymbol{( H )}$ finally disappearing from this region by E21. Labels: v, Ventricle; MGN, medial geniculate nucleus; $\mathrm{RN}$, Raphe nucleus; ON, olivary nucleus; $\mathrm{p}$, pial surface; SC, superior colliculus. Labels were assigned by reference to a developmental atlas (Altman and Bayer, 1995). 


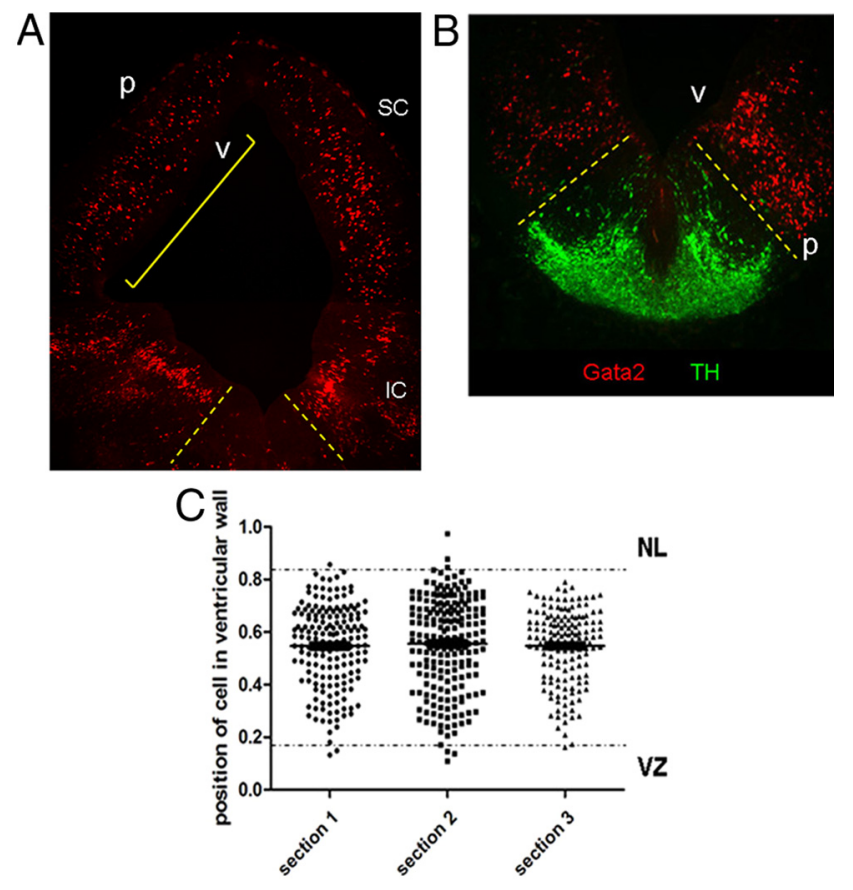

Figure 3. Gata 2 is expressed in the E15 rat midbrain but excluded from catecholaminergic progenitors as well as SC neuronal and VZ layers. $\boldsymbol{A}$, Gata2 immunohistochemistry (red) in E15 rat mesencephalon (dorsal side at the top) labels cells in the IZ around the ventricle, except for the ventral midline (demarcated with dotted lines). The yellow bracket indicates the region where Gata $2+$ cell distances from the VZ were measured for $\boldsymbol{C}$. $\boldsymbol{B}$, Staining for TH (green) indicates that the ventromedial midbrain is the region generating dopaminergic ventral tegmental area (VTA) and substantia nigral (SN) neurons, but that this region lacks Gata2 expression (green). C, Vertical scatter plot of three serial brain sections quantifying the distribution of Gata2 + cells within the E15 dorsal mesencephalon where zero equals the ventricular surface and 1 is the pial surface. The average means and average SDs of the distributions are $0.55 \pm$ 0.16 . Note that the vast majority of the Gata2-expressing population lies between the ventricular zone (VZ) and neuronal layer (NL). The VZ and NL boundaries were determined by average normalized morphological measurements from the ventricle to the edge of the VZ (determined by phase contrast) and the innermost boundary of TUJ1-expressing cells. Labels:v, Ventricle;VZ, ventricular zone; $p$, pial surface; $\mathrm{SC}$, superior colliculus; IC, inferior colliculus; $\mathrm{NL}$, neuronal layer.

and midbrain. We subsequently focused on the dorsal mesencephalon and developing $\mathrm{SC}$ where expression was robust as well as transient, and in which the developmental role of Gata2 is unclear.

The earliest detectable mesencephalic Gata2-expressing cells appear at E12 in the ventrolateral part of this structure (Fig. $2 \mathrm{~A}-$ C). At this and all other times between E12 and E18, Gata2 expression is limited to a domain lying between the ventricular zone of neuroprogenitor cells and the $\beta$-III-tubulin-expressing neuronal layers neurons (Fig. 2). We will refer to this domain as the "intermediate zone" or IZ. By E14, Gata2 expression spreads to the entirety of the IZ in the ventral mesencephalon (Fig. 2A,D). Gata2 is not detected in the dorsal mesencephalon at these times, indicating that it does not play a role in development of earlyborn SC neurons that are present at E12-E14. This is consistent with a report that expression of Gata2 transcripts is absent in the mouse dorsal mesencephalon as early as E8.5 (equivalent to approximately E10.5 in rat) (Nardelli et al., 1999).

After E14, Gata2 expression spreads dorsally and at E15-E17 lies in the IZ in a diffuse pattern around the full mesencephalic circumference (Fig. $2 A, E, F$ ), except for a medial gap in the ventral midbrain (Fig. $3 A$ ). The latter contains cells that are positive for tyrosine hydroxylase and negative for Gata2 and that appear to be immature dopaminergic neuronal cells in process of migra- tion (Fig. 3B). By E18, Gata2 is absent from the ventral midbrain but persists in a thin layer immediately beneath the differentiating SC in the dorsal mesencephalon (Fig. $2 A, G$ ). The IZ lying between the ventricle and $\mathrm{SC}$ is nearly gone by E2 1 and there is no detectable Gata2 expression there by this time (Fig. 2 H). By E17 and beyond, a second wave of strong Gata2 expression appears in subsets of mature neurons within the ventral midbrain including the medial geniculate nucleus and the olivary nuclei (Fig. $2 A$ ).

Gata2-positive cells in the embryonic dorsal mesencephalon appear to be migrating immature, postmitotic neuronal precursors

We further characterized Gata2+ cells in the developing dorsal mesencephalon to better understand their identity. At all times, Gata2 was expressed by only a subpopulation in the IZ. For example, at E15 they comprised $29 \pm 4 \%$ of the cells there, and this proportion appeared to hold through at least E17. Immunostaining for phosphohistone $\mathrm{H} 3$ at $\mathrm{E} 15$ revealed a layer of mitotic cells along the ventricle from which Gata2 was completely excluded, indicating that the Gata2+ population is postmitotic (Fig. 4A). Costaining at this age confirmed that the highest-expressing Gata2 + cells lack $\beta$-III-tubulin (TuJ1) + expression in the IZ (Figs. 3C, 4B). However, a small number of neurons that express low levels of Gata2 and TuJ1 were detected near the IZ/SC boundary, suggesting that these may be in transition with Gata2 expression waning while $\beta$-III-tubulin expression is induced. These findings and distribution of Gata2 + cells suggest that they are immature, postmitotic neuronal precursors migrating to the differentiating SC.

The immature nature of Gata2 + cells was supported by comparison with the expression patterns of Msi1 and Sox2, markers for neuroprogenitor cells and immature neuronal precursors (Kaneko et al., 2000; Sakakibara et al., 2002; Bylund et al., 2003; Graham et al., 2003). Because available antisera precluded costaining, we examined contiguous serial sections. Both Msi1 and Sox2 were present with Gata2 in the VZ at E15, as well as in the IZ (Fig. 4C,D). Whereas both Msi1 and Gata2 extended all the way to the TUJ1-positive SC, Sox2 expression ended several cell diameters short of it. Within the central area of the IZ, essentially all cells were Msi1 + and the vast majority were Sox $2+$. This indicates that most/all Gata2 + cells there also express Sox2 and Msi1.

Pax homeodomain transcription factors confer region-specific patterning in the CNS and are crucial for establishing area boundaries (for review, see Nakamura, 2001). Pax3 and Pax7 are expressed in dorsal midbrain, specifically in the developing SC, initially together within neural progenitors and early postmitotic neuronal precursors (Thompson et al., 2008). In late embryogenesis, their patterns diverge and by birth Pax3 persists in a periventricular arrangement, whereas Pax7 is low around the ventricle and highest in mature SC neurons (Thompson et al., 2004, 2008; Fedtsova et al., 2008). We observed that, in E15 dorsal midbrain, Pax3 and Pax7 expression extends from the VZ into the IZ and ends several cell diameters beneath the neuronal layers (Fig. $5 A, B)$. Thus, Pax 3 and Pax7 are expressed in the IZ along with Gata2+ except in the most superficial part of this zone. Of all Gata2+ cells in the IZ, counts revealed that $50 \pm 6 \%(n=3)$ express Pax 3 , and that within the part of the IZ where these markers overlap, $76 \pm 6 \%$ are also Pax 3 positive. Conversely, $13 \pm 2 \%$ $(n=3)$ of Pax3 + cells in the IZ coexpress Gata2. With the patterns of Pax3 and Pax7 expression being so similar at E15, the coincidence of Gata2 and Pax7 appears to be very similar. Another homeodomain transcription factor Brn3a (Pou4f1) is ex- 
pressed throughout the SC neuronal layers at E15 and E17, but not in the IZ, and does not coexpress with Gata2 (data not shown).

The basic helix-loop-helix (bHLH) proneural gene Ascl1 (Mash1) is expressed in developing mesencephalon (Gradwohl et al., 1996; Kala et al., 2009; Osório et al., 2010) and is partially coexpressed with Gata2 in the IC (Kala et al., 2009). We also observed coexpression of Ascl1 and Gata2 in the dorsal mesencephalon. At E15, dorsal mesencephalic Ascl1 is expressed both in the VZ and IZ and overlaps with Gata2 in the upper regions of the IZ (Fig. 5C). Counts revealed that, where both are present, $46 \pm 9 \%(n=3)$ of Gata $2+$ cells coexpress Ascl $1+$ and that $68 \pm 1 \%$ $(n=3)$ of Mash + cells are also Gata2 + . Together, coexpression of Gata2 in the IZ with Sox2, Msi1, Pax3/7, and Ascl1, but not phosphohistone $\mathrm{H} 3$ or $\beta$-III tubulin supports the idea that Gata2+ cells are postmitotic neuron precursors that are migrating to the SC. Once in the SC, they lose Gata2 expression and complete their differentiation into mature neurons.

The final marker evaluated was the early neuronal migrating cell marker doublecortin (Dcx). In the E15 dorsal mesencephalon, Dcx expression was essentially indistinguishable from that of $\beta$-IIItubulin, and as such, was excluded from the Gata2+ population (Fig. 5D).
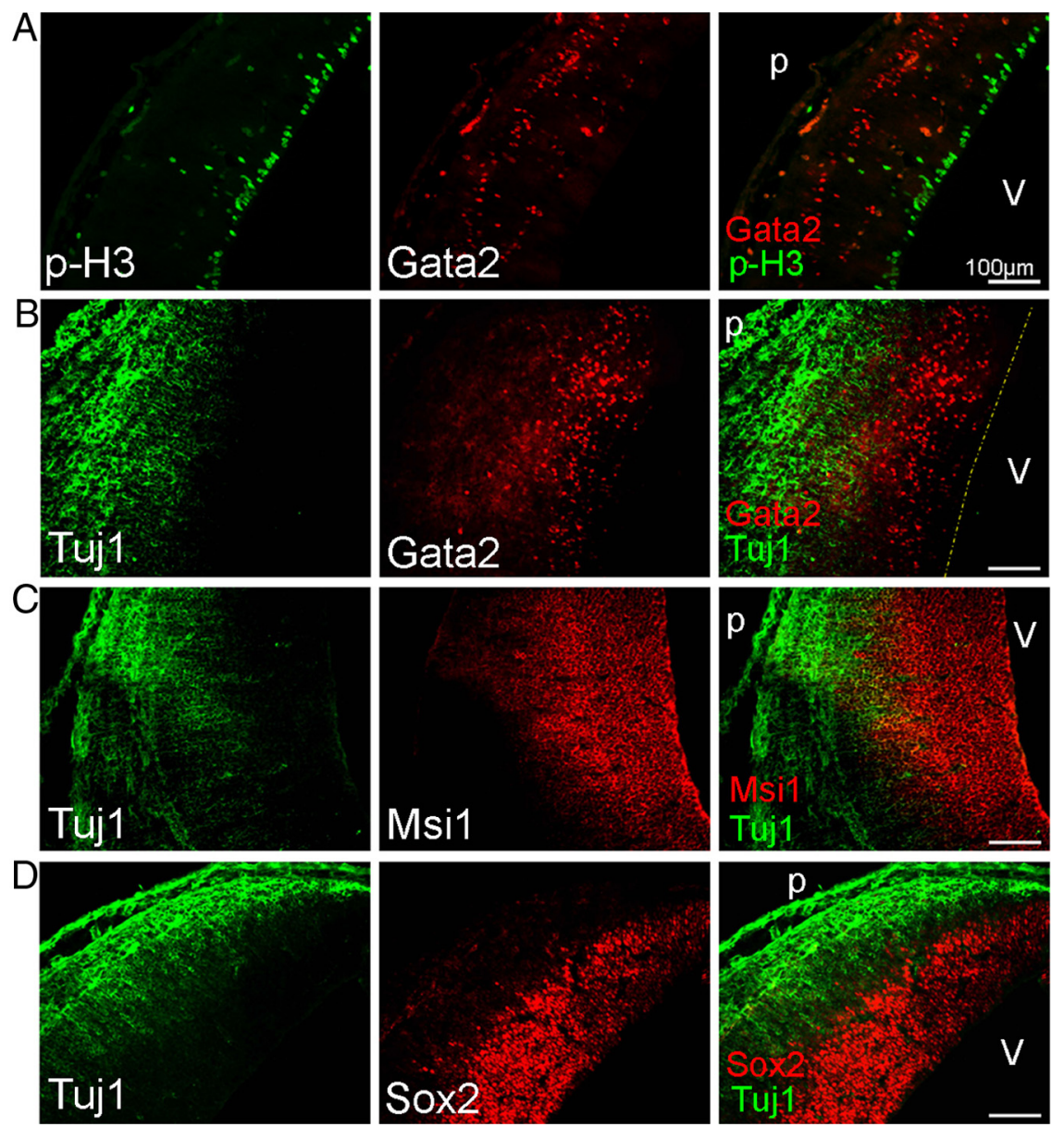

Figure 4. Gata2-expressing cells in the E15 developing SC are postmitotic and immature. Gata2 expression in the E15 rat developing SC is excluded from mitotic progenitor cells immunostaining for phosphohistone $\mathrm{H} 3(\operatorname{Ser} 10)(A)$ and mostly from the $\beta$-III-tubulin (TUJ1)-positive neuronal cell layers ( $\boldsymbol{B})$. In contrast, Gata2 + cells lie in a zone positive for the markers Msi1 $(\boldsymbol{C})$ and Sox2 (D). Labels: v, Ventricle; $p$, pial surface. The dotted line in $\boldsymbol{B}$ indicates position of ventricular surface.

\section{Gata2 knockdown in dorsal}

mesencephalon interferes with cell migration

Because our findings indicate that Gata2 is selectively expressed in immature postmitotic neuronal precursors in the dorsal mesencephalon, we next addressed its functional role there. To achieve this, we designed and characterized independent siRNA constructs targeted against rodent Gata2, but not human Gata2, and expressed them as shRNAs in a vector that also expresses enhanced green fluorescent protein (eGFP). Two of these (siGata2-1 and siGata2-2) show effective knockdown of overexpressed rat Gata2 in HEK293 cells, with siGata2-1 being the most robust (Fig. 6A). In contrast, they did not knock down human Gata2 (Fig. 6A) (data not shown).

Because Gata2 is induced in neuronal precursors as they exit the cell cycle and migrate toward the SC, we used in utero electroporation to test its role in this critical period of dorsal mesencephalic development. Plasmids were injected into the third ventricle at E16 and electrodes were oriented so that DNA was selectively delivered to the dorsal mesencephalon. In this approach, plasmids are electroporated mainly into the neuroprogenitor cells of the VZ that do not express Gata2. These continue to divide or radially migrate out from the $\mathrm{VZ}$ where the expressed Gata2 siRNA should diminish synthesis of endogenous Gata2. For most experiments, animals were killed $5 \mathrm{~d}$ after electroporation and their brains processed by immunofluorescence for expression of eGFP and other markers.
As evidence that our shRNAs were effective, counts revealed a $\sim 75 \%$ decrease in proportion of electroporated cells in the IZ that were positive for endogenous Gata2 after receiving Gata2 shRNA (shControl, 33\% Gata2+, vs siGata2-1, 8.3\% Gata2+). Even in cells with detectable Gata2 after electroporation with Gata2 shRNA, the signal was markedly reduced (data not shown).

Visualization of eGFP at E21 (5 d after electroporation) revealed labeled cells at all levels of the dorsal midbrain for both knockdown and control constructs (Fig. 6B-F). In the chick tectum, deep layer neurons are generated first, followed by a second wave that produces the outermost retinorecipient layers and a third and final wave that generates the interstitial lamina (LaVail and Cowan, 1971; Gray and Sanes, 1991; Sugiyama and Nakamura, 2003). It is unknown whether such neuron generation patterns are similar in rat SC. However, in brains electroporated with control constructs and stained for the neuronal marker NeuN, essentially all $\mathrm{eGFP}+/ \mathrm{NeuN}+$ cells were confined to the middle and outermost laminae of the SC. Conversely, $75 \pm 3 \%(n=3$ brains, $15-35$ cells each) of eGFP + cells in the brains were $\mathrm{NeuN}+$ in these laminae, whereas $<5 \%$ of eGFP + cells in the lower layers of the SC were $\mathrm{NeuN}+$. These findings thus indicate that cells electroporated at E16 correspond to waves 2 and 3 of chick tectal neurogenesis.

Initial observations of knockdown cells indicated impaired migration (Fig. 6B-F). To facilitate comparison between migra- 

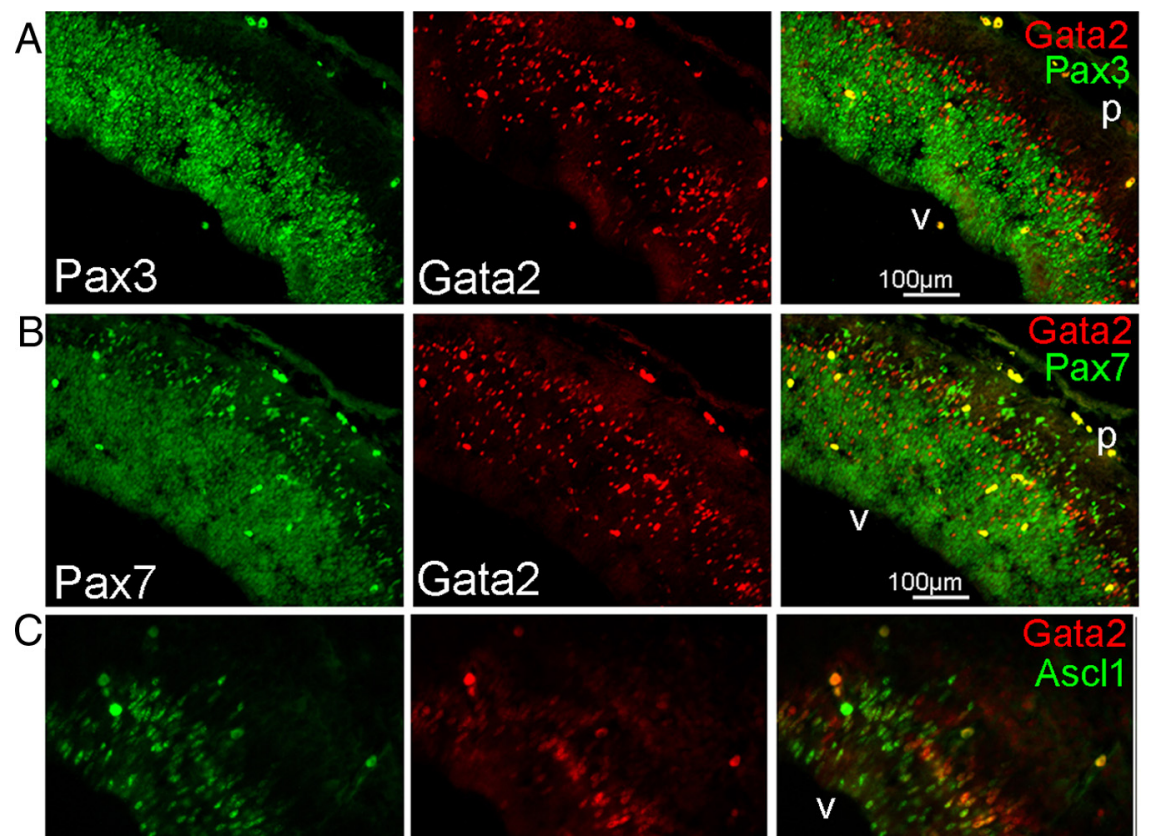

Ascl1
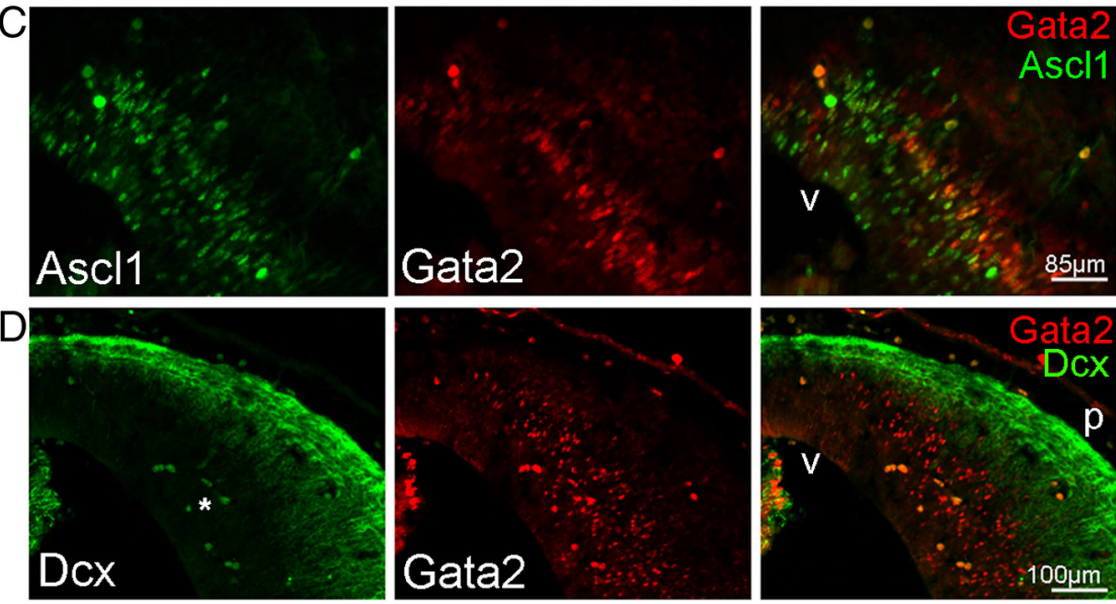

Figure 5. Gata2-expressing cells are early neuron precursors. $\boldsymbol{A}, \boldsymbol{B}$, Immunohistology reveals Gata2 coexpression in the outermost population of Pax3 $+(\boldsymbol{A})$ and Pax7 + cells in the E15 developing SC. Note that Gata2 + cells directly beneath the neuronal layer lack expression of both Pax genes. C, Many Gata2 + cells also express Ascl1 in the E15 developing SC. D, Dcx is expressed in the neuronal area of the E15 developing SC and does not coexpress with Gata2. A cluster of blood cells with nonspecific, dual-label fluorescence is evident (bright yellow cells in the merge panel) and are indicated by an asterisk in the green channel. Labels: $v$, Ventricle; p, pial surface.

tion of control and knockdown cells, we partitioned coronal brain sections along the radial axis into three sectors. Sector A included the portion of dorsal mesencephalon $30 \%$ of the distance from the aqueduct to the pial surface and contained the VZ, a narrow periventricular zone, and the deepest layers of the SC (Fig. 6C). Most electroporated cells in the VZ had a morphology and possessed markers [nestin and brain lipid binding protein (BLBP)] identifying them as radial glia (Fig. 6C-F) (data not shown). These are Gata2 - and appear unaffected by Gata2 shRNAs and were therefore excluded from our subsequent quantifications. Most cells in sector A outside the VZ had the appearance of migrating neuronal precursors with a bipolar or unipolar morphology (data not shown). Gata2 knockdown caused a robust effect on migration so that a large number of electroporated cells appeared to be arrested in the periventricular area of sector A where endogenous Gata2 is expressed during development (Fig. $6 E, F)$. Quantification indicated that, whereas $\sim 35-45 \%$ of control electroporated cells were in sector A, $60-75 \%$ of knockdown cells were located there (Fig. $6 B$ ). The difference was greater with siGata2-1 than for siGata2-2 shRNA, which is consistent with their relative efficacy for knocking down Gata2 (Fig. 6A).

Sector B included the portion of the dorsal mesencephalon between 31 and $60 \%$ of the distance to the pial surface and contains the central layers of the SC. Sector C comprised the remain- ing $61-100 \%$ of the distance to the pial surface and contains the retinorecipient layers of the SC. Whereas Gata2 knockdown did not significantly affect the proportion of labeled cells in sector B, it markedly reduced (by approximately two-thirds) the proportion of electroporated cells that reached sector $C$ (Fig. $6 B, E, F)$.

The loss of cells migrating into the outermost layers of the SC promoted by knockdown of Gata2 could be attributable to several potential causes, including cell death. Gata2 expression is required for normal survival and expansion of hematopoietic cells (Tsai et al., 1994; Rodrigues et al., 2005). Additionally, the GATA factor Gata3 is downstream of Gata2 in sympathetic neuron differentiation and loss of Gata3 in developing (Tsarovina et al., 2004) and in mature sympathetic neurons (Tsarovina et al., 2010) negatively impacts survival. To assess whether the observed effect of Gata2 knockdown in the superior colliculus might be attributable to excessive cell death, we electroporated at E16 and killed the animals at E18 for a $2 \mathrm{~d}$ time point. Immunostaining of siCon control, siGata2-1, or siGata2-2 electroporated brains were performed using the markers PH2A.X and cleaved caspase 3, which have been shown to correlate well with apoptotic cell death (Holubec et al., 2005). A small number of PH2A.X + and cleaved caspase $3+$ cells were observed in each 50 $\mu \mathrm{m}$ SC section, which indicates that the staining was successful. However $<1 \%$ of the electroporated cells stained for these markers and no difference was observed for such staining of cells electroporated with either the siGata2$1 / 2$ or control constructs (data not shown). In addition, if the absence of GFP + cells in the outer SC layers in Gata2 knockdown brains was attributable to cell death, substantially fewer total labeled cells would be observed in these brains compared with siCon controls. However, the distribution patterns of cells in siRNA electroporated brains (Fig. $6 C-F$ ) are consistent with redistribution of Gata2 knockdown cells, rather than cell loss. Together, these findings support the conclusion that cell death does not account for the absence of Gata2 knockdown cells in the SC outer laminae and suggest the alternative that Gata2 is required for proper migration of SC neuronal precursor cells to these layers.

As a control for possible off-target shRNA effects, we performed rescue experiments in which a plasmid expressing human Gata2 was coelectroporated with siGata2-1 or siGata2-2 shRNA. Pairwise comparison of human (hGata2) and rat Gata2 (rGata2) DNA sequences predicts that siGata2-1 and siGata2-2 should knock down the rat, but not human form, although the two are 98\% homologous at the protein level. As discussed below, expression of hGata2 itself did not perturb migration of cells into the SC.

In contrast to the effect of electroporating cells with either siGata2-1 or siGata2-2 alone, there was no evident accumulation 

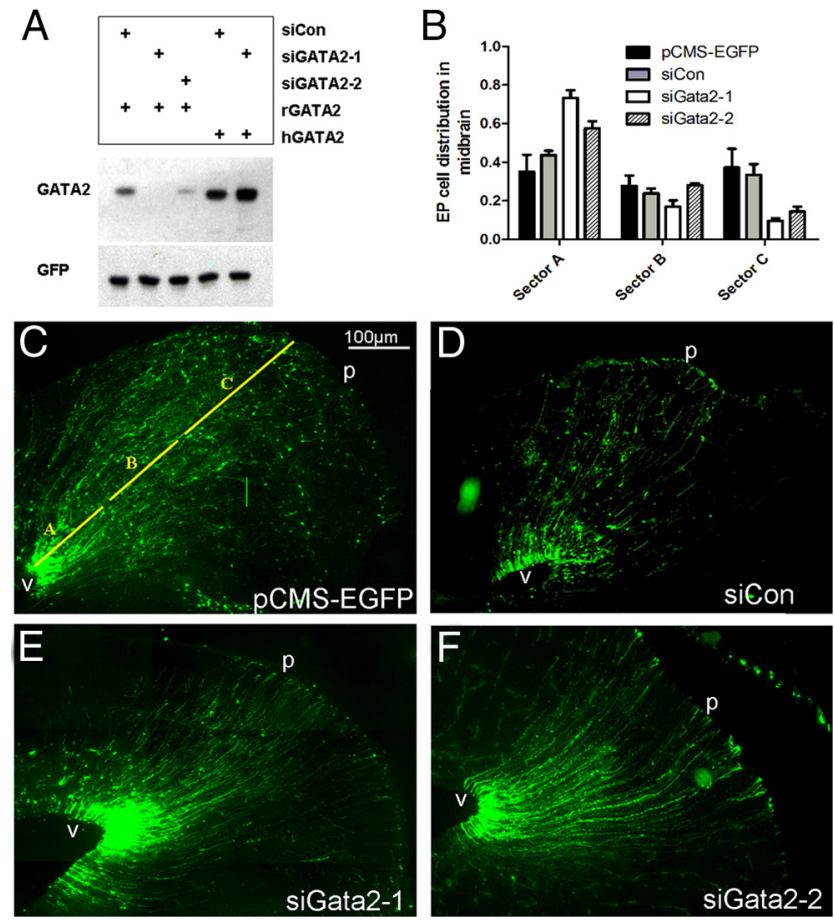

Figure 6. Transient Gata2 expression is required for normal migration of early neuron precursors in the developing SC. $\boldsymbol{A}$, Gata2 siRNA knocks down rat, but not human Gata2. HEK293 cells were transfected with either rat Gata2 ( $r$ Gata2) or human Gata2 (hGata2) and either siCon (control), siGata2-1, or siGata2-2 as indicated. In a comparable experiment, siGata2-2 also lacked hGata2 knockdown activity (data not shown). B, Knockdown of Gata2 in the developing $\mathrm{SC}$ affects cell migration. The indicated eGFP-expressing constructs were electroporated into the dorsal midbrains of E16 rat embryos and brains were harvested at E21. The normalized distances of electroporated cell migration were measured and sorted into three zones: sector $A$, $0-30 \%$ of the distance between the ventricle and pial surface; sector $B, 31-60 \%$; sector $C$, 61-100\%. Values indicate mean percentage of electroporated cells in each sector \pm SEM $(n=$ 3 brains). In sector A, the proportions of siGata2-1 and siGata2-2 electroporated cells present were significantly greater from those expressing siCon control vector ( $t$ test, $p=0.003$ and $p=$ 0.03 , respectively). Similarly, the proportions of siGata2- 1 and siGata2-2 electroporated cells in sector C were markedly reduced compared with siCon control ( $t$ test, $p=0.014$ and $p=0.037$, respectively). There was no statistical significance between the proportions of cells found in any condition in sector B. $\boldsymbol{C}-\boldsymbol{F}$, Representative images of eGFP expression in brains electroporated with pCMS-EGFP $(\boldsymbol{C})$, siCon pCMS-EGFP control $(\boldsymbol{D})$, or Gata2 knockdown constructs siGata2-1 $(\boldsymbol{E})$ or siGata2-2 $(\boldsymbol{F})$. The yellow lines in $\boldsymbol{C}$ indicate positions of sectors A, B, and C. Ventricle is at bottom left corner of images. Labels: $v$, Ventricle; $p$, pial surface.

of cells in sector A after electroporation with siGata2-1/hGata2 or siGata2-2/hGata2 (Fig. 7A) (data not shown). Moreover, for brains matched for electroporation efficiency, cells receiving siGata2-1/hGata2 or siGata2-2/hGata2 reached sector B/C in numbers comparable with that for control vector and that were approximately threefold higher compared with brains receiving only siGata2-1 or siGata2-2 (Fig. 7C,D). Coimmunostaining indicated that $65 \%$ of the electroporated cells that reached sectors $\mathrm{B} / \mathrm{C}$ in the rescue study were $\mathrm{NeuN}+($ Fig. $7 E$ ), a level similar to that for brains electroporated with control constructs (75\%).

\section{Effects of exogenous Gata2 expression in the dorsal mesencephalon}

Because Gata2 knockdown arrests migration of SC precursor cells, we next assessed the potential effects of electroporation with Gata2 expression constructs. Migration of cells electroporated with rat or human Gata2-FLAG pCMS-EGFP at E16 and harvested at E21 showed no significant change in migration relative to control electroporated cells (data not shown). Expression of exogenous Gata2 was verified by immunofluorescence against Gata2 protein and the FLAG epitope, and robust expression was found in many cells at E21 (Fig. 7B) (data not shown). However, the expression pattern of exogenous Gata2-FLAG protein in the SC was somewhat unexpected in that not all GFP+ cells were positive for Gata2/FLAG (Fig. 7B). Expression was detected only in a subset of electroporated cells in the deep layers (sector A) of the SC and no exogenously expressed protein was found in electroporated cells within sectors B or C. Comparable results were found with both rat Gata2 and human Gata2. These observations suggest that expression of Gata2 protein may be subject to differential posttranslational mechanisms in the SC and that translation or stability of Gata2 protein may be diminished in specific neuronal populations. This mechanism could explain in part why endogenous Gata2 protein levels dramatically fall when neuronal cells enter the SC and the apparent lack of effect of exogenous Gata2 on neuronal migration. The capacity of hGata2 to fully rescue from knockdown of endogenous Gata2 further indicates that sufficient levels of the human protein are expressed in the IZ during the critical period before E21 to promote proper migration and differentiation.

\section{Gata2 knockdown in the dorsal mesencephalon interferes} with differentiation of neuronal precursors

The above findings indicate that Gata2 plays an important role in permitting migration of immature neuronal precursors from the IZ into the SC. To discern whether loss of Gata2 limits migration alone or whether this is in addition to or secondary to impingement on postmitotic precursor differentiation, we performed additional marker analyses of the electroporated cells. One possibility was that Gata2 loss causes precocious differentiation of precursors into mature neurons, which in turn impairs migration. However, both knockdown and control electroporated cells in sector A lacked expression of neuronal markers $\beta$-III-tubulin or NeuN (Fig. $8 A, B$ ).

The appearance of endogenous Gata2 protein in postmitotic neuronal precursors raises the possibility that it is necessary for cell cycle exit, as reported in the chick spinal cord (El Wakil et al., 2006) and that its knockdown may induce cells outside the VZ to remain in or reenter the cell cycle. However, Ki67 staining indicated that Gata2 loss did not block proliferation within the $\mathrm{VZ}$ or stimulate mitosis outside the VZ (data not shown) (Fig. 8C). Moreover, cells in sector A outside the VZ that were electroporated with Gata2 shRNAs were negative for the radial glial marker BLBP (Fig. 8D).

Because Gata2 is highly expressed in immature neuronal precursors, we reasoned that it might play a role in their differentiation into mature neurons and that Gata2 loss would result in retention of coexpressed markers such as Ascl1 and Pax3/7 that are present before its induction and that are extinguished in SC neurons. At E21, endogenous Ascl1 is sparsely expressed within, and is limited to, a four to five cell deep zone in sector $A$ at the junction between the $\mathrm{VZ}$ and the deepest neuronal layers of the SC. This mostly corresponds with the area of greatest migration arrest caused by Gata2 knockdown. For cells electroporated with control or Gata2 shRNAs, all Ascll expression was within this zone. Strikingly, Gata2 knockdown increased the proportion of electroporated cells in this region that were Ascl1 + by twofold to threefold (Fig. 8E, G).

The endogenous expression pattern of Pax3 at E21 is quite different from Ascl1 and includes nearly all cells within the VZ and within sector A below the neuronal layers of the SC. In addition, all neuronal layers in the SC (i.e., within sectors A-C) con- 

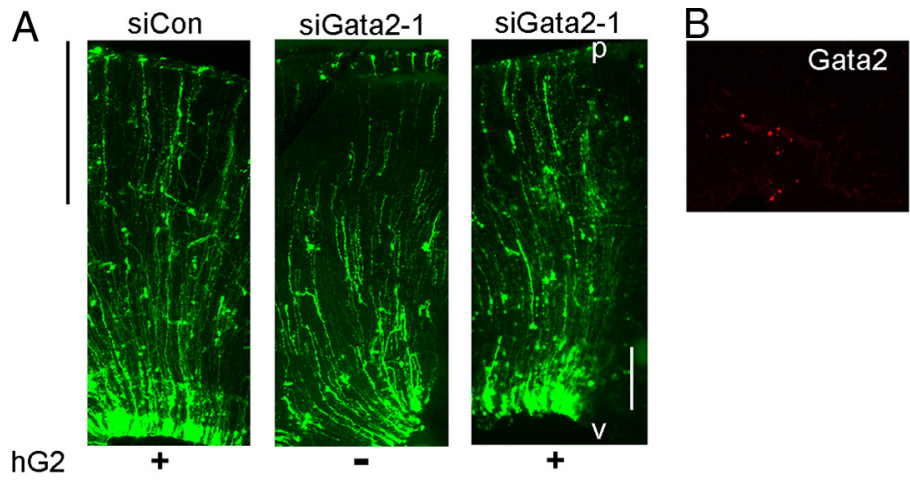

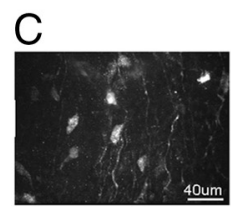

siCon

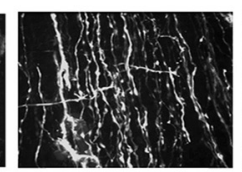

siGata2-1

D

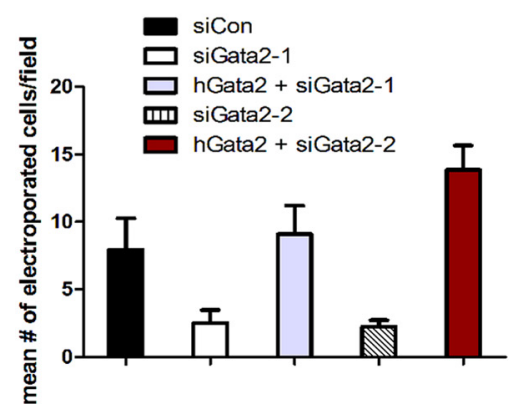

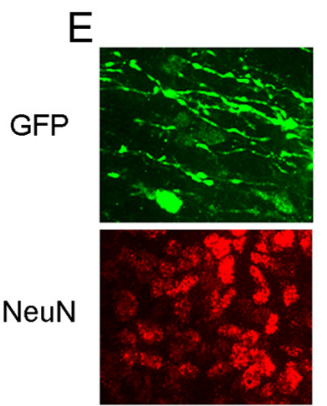

Merge

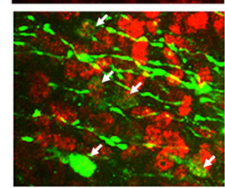

Figure 7. Human Gata2 (hGata2) rescues migration and differentiation of siGata2 knockdown cells. $\boldsymbol{A}$, Coelectroporation of hGata2 with siGata2-1 allows cells to overcome knockdown of endogenous Gata2 and migrate to the SC outer laminae. The vertical black line to the left of the panel indicates the region where cell migration is rescued and where data were collected for $\boldsymbol{C}$. White scale bar, $75 \mu \mathrm{m}$. Electroporation, E16; harvest, E21 (here and in subsequent panels). $\boldsymbol{B}$, Immunofluorescent staining for Gata2 and GFP expression detects Gata2 in cells electroporated with hGata2 and siGata2-1. Area shown is within sector A where endogenous Gata2 in not expressed at E21. The dotted lines show position of ventricular surface. $\boldsymbol{C}, \boldsymbol{D}$, Electroporation with hGata2 rescues migration defect in sectors B/C caused by knockdown of endogenous Gata2. C shows GFP + cells in sector B/C. Cells electroporated with siCon or siGata2-1 and hGata2 have a neuronal morphology, whereas a brain receiving only siGata2 contains only radial glial fibers. $D$ shows numbers of electroporated cell bodies per field in each condition, and values are means \pm SEM $(n=3$; Student's $t$ test values of siGata2-1/hGata2 and siGata2-2/hGata2 compared with siGata2-1 or siGata2-2, respectively, were $p=0.048$ and $p=0.003$, respectively). There were no statistical differences between the values for siCon, siGata2-1/hGata2, and siGata2-2/ hGata2. $\boldsymbol{E}$, hGata2-1-rescued cells present in sectors $\mathrm{B} / \mathrm{C}$ include NeuN + neurons. The arrows indicate $\mathrm{GFP}+/ \mathrm{NeuN}+$ cells. Labels: $v$, Ventricle; $p$, pial surface.

tain a sparse population of Pax3 cells. Examination of electroporated cells for Pax3 revealed no expression within sectors $\mathrm{B}$ and $\mathrm{C}$, regardless of whether they received control or siGata2 plasmids (data not shown). However, Pax3 was present in a subpopulation of electroporated cells within the neuronal layers of sector A and the proportion of such cells was 2.5-fold higher for those receiving siGata 2 compared with those receiving control plasmid (Fig. $8 F, H$ ). We also examined Pax7, which showed strong expression in a subpopulation of neurons within sectors $\mathrm{B}$ and $\mathrm{C}$, but was absent from sector A. In contrast to Pax3, Pax7 was absent from cells in sector A electroporated with either control or Gata2 shRNA plasmids.

We additionally assessed Sox 2 and Msi1, which are coexpressed at E15 with Gata2. At E21, Sox2 is present in all VZ cells and in isolated cells distributed throughout the SC. The majority of both knockdown and control cells present in sector A were Sox $2+$. In contrast, by E21 Msi1 expression was restricted to the
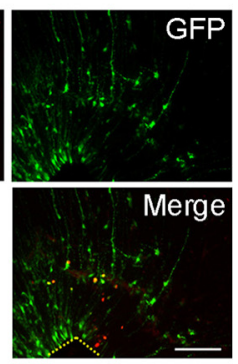

VZ and absent from Gata2 knockdown or control cells (data not shown).

To determine whether Gata2 knockdown cells persist in an immature state, animals electroporated at E16 with siGata2-1 were allowed to develop until P5 when SC neurogenesis is nearly complete. Similarly to E21, the Gata2 knockdown cells in the deep layers of the SC at P5 were still positive for $\mathrm{Pax} 3$ and Sox 2 (Fig. 9), and exhibited an immature radially oriented unipolar and bipolar morphology. In contrast, Ascll and Msil were undetectable. Together, these findings support the idea that Gata2 plays a critical role in differentiation of postmitotic neuronal precursor cells in the dorsal mesencephalon and that its loss arrests them at an early stage of maturation characterized by retention of Pax3 and Sox2.

\section{Discussion}

Gata2 is expressed in postmitotic dorsal midbrain neuronal precursors

Although Gata2 plays a central position in hematopoiesis and stem cell maintenance (Shimizu and Yamamoto, 2005), its function within neural tissues has only recently come into focus. Evidence suggests that Gata2 operates in discrete neuronal subtype lineages and first appears during intermediate stages of differentiation after commitment to a neuronal fate. In some cases, expression is transitory and downregulated before terminal differentiation (mesencephalic precursors) and in others is retained in differentiated cells (serotonergic and V2 spinal interneurons). In another instance, $\mathrm{r} 4$ vestibuloacoustic neurons, Gata2 directs axon pathfinding (Bell et al., 1999; Nardelli et al., 1999). It thus appears that the roles of Gata2 in neuronal cells are both varied and subtype dependent.

Gata2 was detected in a restricted pattern in developing chick optic tectum (Kornhauser et al., 1994) and mouse SC (Zhou et al., 2000) that decreased with differentiation (Herberth et al., 2005). Kala et al. (2009) also reported transient Gata2 expression in developing mouse midbrain. A detailed description of Gata2 protein expression in developing mammalian dorsal midbrain has not been previously presented. Our findings confirm widespread transient midbrain expression in embryonic rat.

One excluded population was ventral tyrosine hydroxylasepositive neurons; Gata2 has been detected in human substantia nigra and in cultured midbrain dopaminergic neurons, and dopaminergic cell lines (Scherzer et al., 2008; Polanski et al., 2010). This suggests that expression in such neurons appears at a relatively late developmental stage. In consonance, we noted emergent Gata2 expression in ventral midbrain structures during late embryogenesis. Thus, in midbrain, both Gata2 regulation and function appear to differ among neuronal subtypes. 
In rat dorsal mesencephalon, the earliest Gata2 expression appeared at E15. The deep-layer periventricular SC neuronal population has formed by this stage, so Gata2 does not appear necessary for their differentiation. From E15 to E18, positioning of Gata2+ cells in dorsal midbrain beneath the neuronal layer but above the proliferating VZ, along with coexpression with immature markers, indicates that Gata2 is expressed in postmitotic neuronal precursors migrating to the superficial laminae of the SC.

One emerging theme is that Gata2 is induced in postmitotic neuronal precursors expressing bHLH proneural and homeodomain transcription factors. In developing sympathetic ganglia, Gata2 is induced after sequential expression of Ascl1, Phox $2 \mathrm{~b}$, Phox $2 \mathrm{a}$, and Hand2, but before catecholaminergic markers (Groves et al., 1995). Gata2 loss-of-function in chick reduces sympathetic ganglion size and tyrosine hydroxylase and SCG10 expression (Tsarovina et al., 2004). Gata2 is also coexpressed with Ascl1 and the bHLH transcription factor Helt in early ventral midbrain (Kala et al., 2009). In hindbrain and early IC, Gata2 is induced in Nkx2.2 and Nkx6.1-expressing progenitors and acts to specify serotonergic and GABAergic fate, respectively (Craven et al., 2004; Kala et al., 2009).

Gata2 can be dynamically regulated throughout cell cycle (Koga et al., 2007), and its electroporation into chick spinal cord induces precocious differentiation and cell cycle exit (El Wakil et al., 2006). However, as in ventral midbrain (Kala et al., 2009), in dorsal midbrain, we observed that Gata2 first appears after cell cycle exit and that Gata2 knockdown has no effect on proliferation within or outside of the VZ.

\section{Gata2 is essential for migration and} differentiation of neuronal precursor cells that populate the SC retinotectal laminae

We used in utero shRNA electroporation to interfere with Gata2 induction in neuronal precursors after their exit from the VZ. This approach permits labeling and tracking of individual cells in which Gata2 protein levels have been manipulated. Dorsal midbrain progenitors electroporated with pCMS-EGFP at E16 generate cells that, based on their positions at E20, colonize the middle and outermost laminae of the SC. These appear to correspond to the second and third waves of developmental migration described in chick optic tectum (LaVail and Cowan, 1971; Sugiyama and Nakamura, 2003).

Gata2 knockdown at E16 greatly diminished the proportion of cells migrating to the retinorecipient laminae of the SC. Thus, Gata2 plays an essential role in development of this important
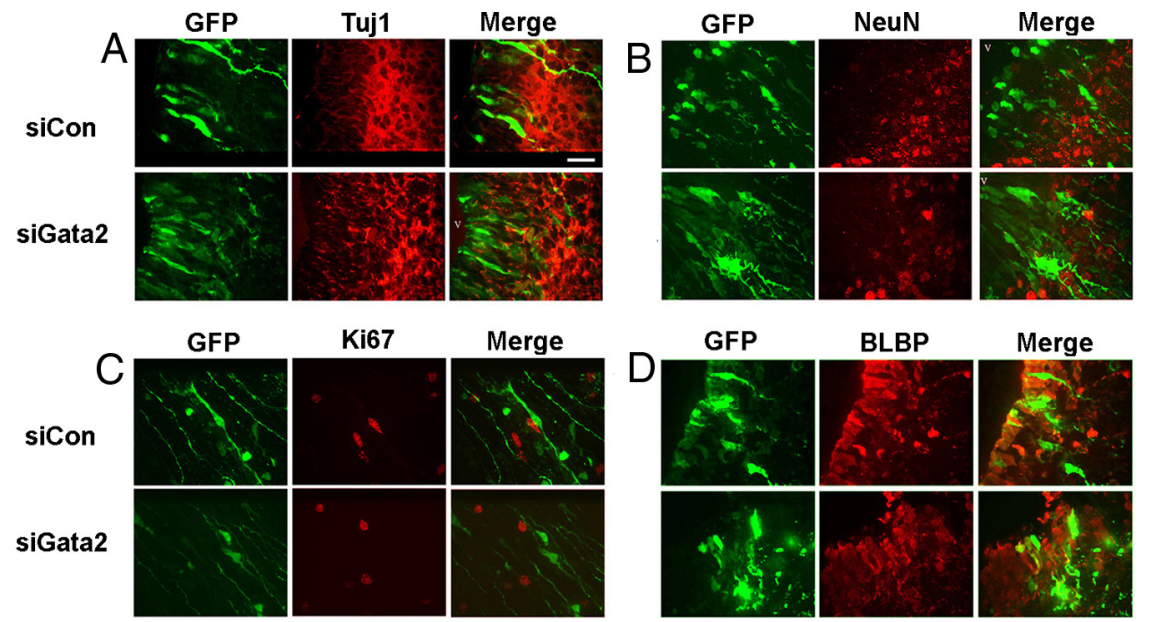

BLBP
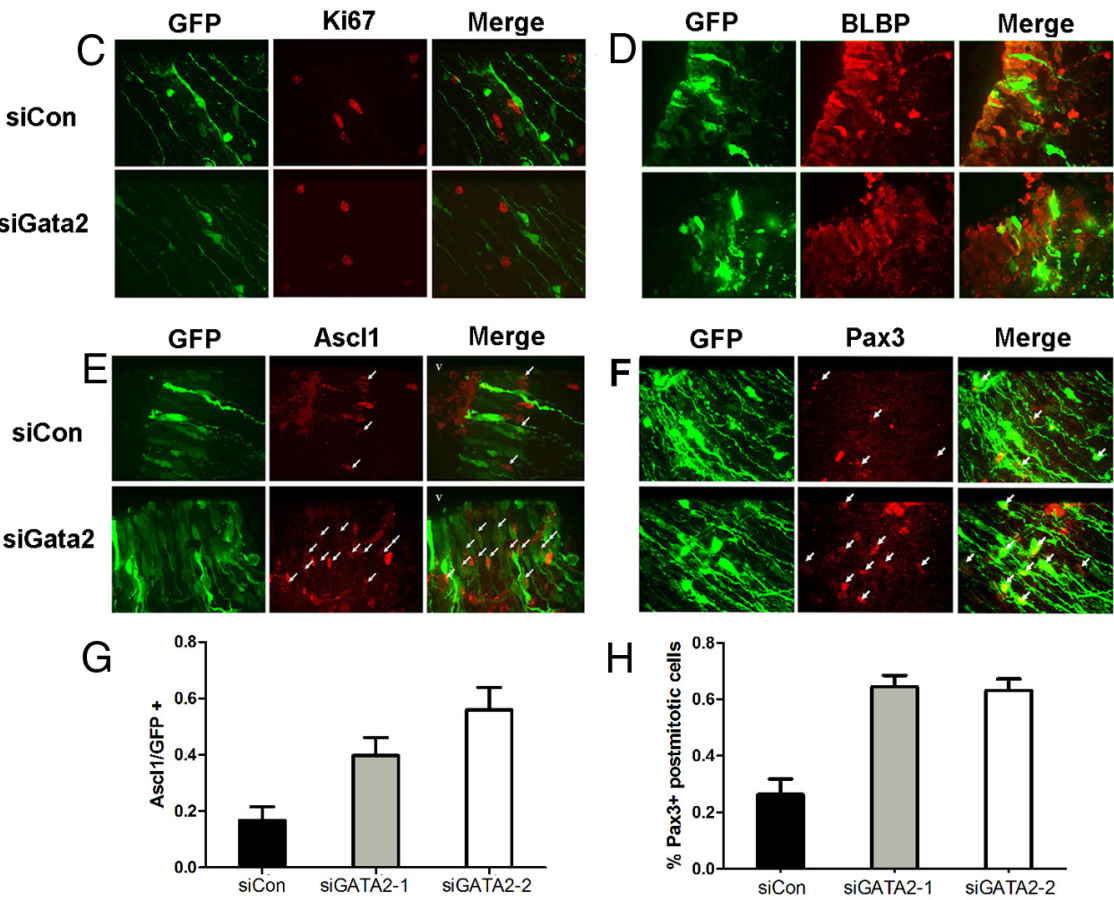

Figure 8. Gata2 is required for differentiation of $\mathrm{SC}$ neural precursors. Dorsal midbrain cells electroporated with siCon or siGata2-1 at E16 and harvested at E21 lack expression of $\beta$-III-tubulin $(\boldsymbol{A})$ and $\operatorname{NeuN}(\boldsymbol{B})$ in the area between the VZ and deep-laye midbrain sector A outside the VZ are Ki67 - , regardless of receiving siCon or siGata2-1. D, Expression of radial glial marker BLBP in dorsal midbrain is unaffected by shRNA-mediated knockdown of Gata2, since cells in the VZ (arrows), but not outside of the VZ, exp high levels of BLBP after electroporation with either siCon or siGata2. E, Knockdown of Gata2 in dorsal midbrain causes accumulation of Ascl1 + cells at the interface of the VZ and the deepest neuron layer of the SC. The arrows show locations of eGFP + /Ascl1 + cells. F, Knockdown of Gata2 increases the proportion of Pax3 + cells in dorsal midbrain sector A outside of the VZ. Graph shows proportions of eGFP + cells in sector A expressing Ascl1 after electroporation with the indicated constructs. A total of 100-300 electroporated cells were evaluated per brain ( $n=3$ brains). Values are means \pm SEM $(n=3-5$ brains; ANOVA, $p=$ . Was for Pax3 (ANOVA, $p=0.002$; Student's $t$ test of siGata2- 1 and siGata2-2 compared with siCon control are $p=0.005$ and $p=0.006$, respectively). In this figure, where the label siGata2 is used, the cells shown are expressing siGata2-1, but the results shown are also representative of results with siGata2-2.

neuronal population. However, those electroporated cells reaching these laminae appeared morphologically typical and were $\mathrm{NeuN}+$, indicating normal migration and differentiation. This could reflect either the timing or extent of Gata2 knockdown or that Gata2 is required for migration and differentiation of only a subpopulation of neurons in these laminae.

We observed little or no effect of Gata2 knockdown on the proportion of cells reaching the middle strata of the SC (sector B). It is possible that such neurons do not require Gata2 for migration and differentiation or that they were destined for the outer laminae but failed to properly migrate/differentiate. Characterization of Gata2 knockdown cells in the middle laminae yielded ambiguous results; those receiving siGata2-1 were NeuN-, whereas those electroporated with siGata2-2 were NeuN +. Although 

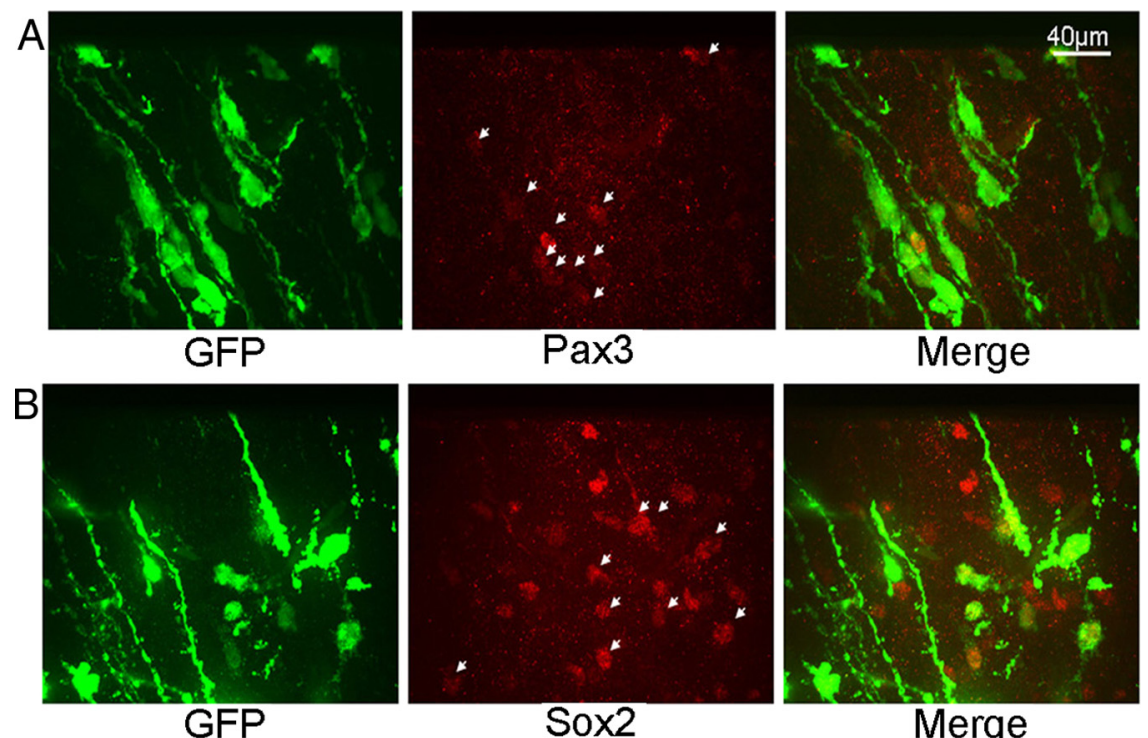

Sox2

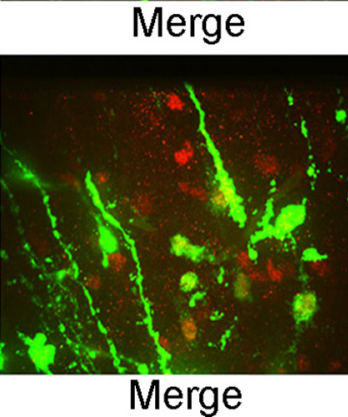

Figure 9. Pax3 and Sox2 expression are retained in Gata2 knockdown cells postnatally. Animals electroporated with siGata2-1 at E16 were harvested at P5. Similar to observations in E21, the majority of labeled cells at this stage were situated in sector A outside the VZ and still exhibited unipolar or bipolar morphology. Immunofluorescence labeling also shows that the majority of knockdown cells still express $\operatorname{Pax} 3(\boldsymbol{A})$ and Sox2 $(\boldsymbol{B})$. The ventricular surface is $\sim 100 \mu \mathrm{m}$ out of view in the direction of the bottom right of the panel, and the pial surface is several hundred micrometers past the top left of the panel.

A

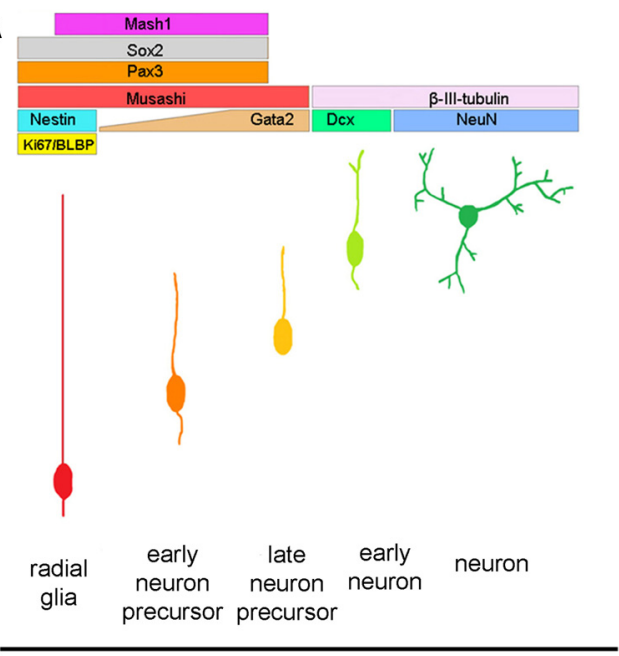

Gata2+
B

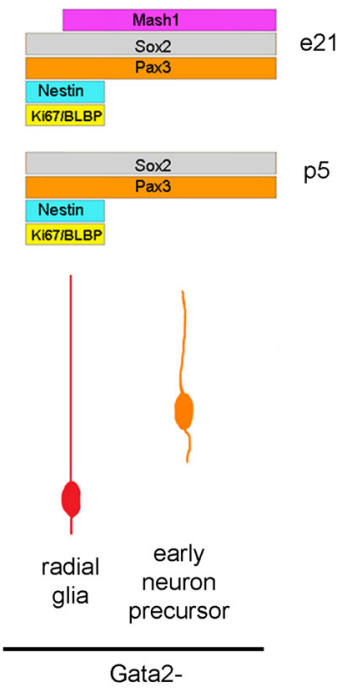

Gata2-

Figure 10. Model of Gata2 expression and function in the developing SC. A, During embryonic dorsal midbrain neurogenesis from E15 to E18, cells pass from a radial glial stem cell identity through an increasingly refined set of neuronal precursors before becoming mature neurons. Each stage shows a characteristic set of markers as indicated. $\boldsymbol{B}$, Disruption of Gata 2 induction impedes the neuronal maturation and arrests cells in a state characteristic of an immature neuronal precursor.

this may reflect the difference in efficacy between the two constructs, we cannot presently draw a clear interpretation.

Although Gata2 knockdown significantly reduced migration of cells to the outer SC, it conversely increased the proportion that inappropriately migrated and that accumulated in the periventricular zone and lower laminae of the SC. Marker studies indicated that these were nonmitotic and neither radial glia nor neurons. Rather, a substantial proportion retained Ascl1, Sox2, and Pax3 at E21 and Pax3 and Sox2 at P5. This phenotype strongly suggests that Gata2 loss traps cells in a neuronal precursor state that fails to further mature or to properly migrate. Gata2 therefore appears necessary for transition of neuronal precursors into those neurons that populate the retinorecipient laminae of the SC. This function is distinct from that in early ventral midbrain where Gata 2 is required for selection between GABAergic and glutamatergic fates (Kala et al., 2009). Of potential relevance, Gata2 expression is subject to differential use of regulatory elements in dorsal and ventral midbrain (Nozawa et al., 2009).

Coexpression of Gata2 with Ascl1, Sox2, and Pax3 and their retention in Gata2 knockdown cells raises the possibility of reciprocal regulation. In ventral midbrain, Helt (but not Ascl1) is required for early Gata2 induction (Kala et al., 2009). The mechanisms of Gata2 induction in dorsal midbrain remain to be seen. Ascl1, Sox2, and Pax3 are expressed in the $\mathrm{VZ}$ where Gata2 is absent, indicating that they are not sufficient to induce Gata2. However, expression of these factors is extinguished just below the deepest layers of the SC in cells still expressing Gata2. This raises the possibility that Gata2 suppresses Ascl1, Pax3, and/or Sox2 expression in late neuron precursors before they fully differentiate. Consistent with this, a substantial proportion of Gata2 knockdown cells retained these factors.

It is presently unclear whether Pax3 and Sox 2 retention by Gata 2 knockdown cells merely reflects their immature nature, or whether such markers help maintain this state. Of potential relevance, Pax3 overexpression in neural tube interferes with differentiation of floor plate and mesencephalon and reduces production of thoracic motoneurons (Tremblay et al., 1996). Moreover, knockdown studies indicate that, in ND7 cells, Pax3 prevents neuronal differentiation (Reeves et al., 1999). Also, activated Sox2 overexpression in cortex inhibits neurogenesis (Bani-Yaghoub et al., 2006).

We found that electroporation with Gata2 failed to affect normal neuronal migration or differentiation. Interestingly, immunofluorescence detected exogenous Gata2 only in a subset of transfected cells within sector A. This was not attributable to faulty vector expression since hGATA2 robustly rescued cells from defects caused by mGata2 shRNAs. Rather, the absence of detectable exogenous Gata2 in electroporated cells within sectors B and C suggests a stringent control over Gata2 protein expression in SC neurons. One possibility is degradation, supported by findings that Gata2 undergoes rapid proteasomal turnover in various cellular contexts (Minegishi et al., 2005; Koga et al., 2007; Lurie et al., 2008). This may be relevant to the extinction of Gata2 expression as neuron precursors enter the SC and mature. However, transcriptional downregulation of endogenous Gata2 also seems likely, as occurs in NGF-treated PC12 cells.

Gata2 function is associated with the bHLH cofactor stem cell leukemia (SCL)/Tal1, which is crucial in blood progenitors to 
confer binding specificity to target genes. During hematopoiesis, Gata2 induces SCL (Chan et al., 2007; Lugus et al., 2007), acts combinatorially with SCL (Wadman et al., 1997), and colocalizes on chromatin with SCL (Wozniak et al., 2008). SCL is expressed in midbrain neuronal precursors and SC cells (van Eekelen et al., 2003; Bradley et al., 2006) and loss of SCL expression in neuronal precursors impairs SC development and causes visual impairment (Bradley et al., 2006). These findings suggest that Gata2 and SCL function together to regulate differentiation of neuronal precursors destined for the SC.

In summary, during dorsal midbrain neurogenesis, cells pass through stages of lineage commitment. Postmitotic neuronal precursor cells within the dorsal midbrain express Gata2 and lose such expression when they further differentiate into neurons that populate the retinorecipient layers of the SC. (Fig. 10). Such expression is necessary for normal migration and differentiation. When Gata2 induction is prevented, precursor cell differentiation is arrested and they fail to undergo transition to retinorecipient SC neurons. It remains to be seen whether these effects on differentiation and migration are independent of one another or whether they reflect the same defects.

\section{References}

Aletta JM, Angeletti R, Liem RK, Purcell C, Shelanski ML, Greene LA (1988) Relationship between the nerve growth factor-regulated clone 73 gene product and the 58-kilodalton neuronal intermediate filament protein (peripherin). J Neurochem 51:1317-1320.

Altman J, Bayer SA (1995) Atlas of prenatal rat brain development. Boca Raton, FL: CRC.

Bani-Yaghoub M, Tremblay RG, Lei JX, Zhang D, Zurakowski B, Sandhu JK, Smith B, Ribecco-Lutkiewicz M, Kennedy J, Walker PR, Sikorska M (2006) Role of Sox 2 in the development of the mouse neocortex. Dev Biol 295:52-66.

Bell E, Lumsden A, Graham A (1999) Expression of GATA-2 in the developing avian rhombencephalon. Mech Dev 84:173-176.

Biswas SC, Zhang Y, Iyirhiaro G, Willett RT, Rodriguez Gonzalez Y, Cregan SP, Slack RS, Park DS, Greene LA (2010) Sertad1 plays an essential role in developmental and pathological neuron death. J Neurosci 30:3973-3982.

Bradley CK, Takano EA, Hall MA, Göthert JR, Harvey AR, Begley CG, van Eekelen JA (2006) The essential haematopoietic transcription factor Scl is also critical for neuronal development. Eur J Neurosci 23:1677-1689.

Bylund M, Andersson E, Novitch BG, Muhr J (2003) Vertebrate neurogenesis is counteracted by Sox1-3 activity. Nat Neurosci 6:1162-1168.

Chan WY, Follows GA, Lacaud G, Pimanda JE, Landry JR, Kinston S, Knezevic K, Piltz S, Donaldson IJ, Gambardella L, Sablitzky F, Green AR, Kouskoff V, Göttgens B (2007) The paralogous hematopoietic regulators Lyll and Scl are coregulated by Ets and GATA factors, but Lyll cannot rescue the early Scl ${ }^{-1-}$ phenotype. Blood 109:1908-1916.

Craven SE, Lim KC, Ye W, Engel JD, de Sauvage F, Rosenthal A (2004) Gata2 specifies serotonergic neurons downstream of sonic hedgehog. Development 131:1165-1173.

Cunningham ME, Kitajewski JK, Greene LA (2001) Efficient generation of stable pheochromocytoma (PC12) cell lines using a recombinant retrovirus (LNC). Methods Mol Biol 169:135-147.

El Wakil A, Francius C, Wolff A, Pleau-Varet J, Nardelli J (2006) The GATA2 transcription factor negatively regulates the proliferation of neuronal progenitors. Development 133:2155-2165.

Fedtsova N, Quina LA, Wang S, Turner EE (2008) Regulation of the development of tectal neurons and their projections by transcription factors Brn3a and Pax7. Dev Biol 316:6-20.

Gradwohl G, Fode C, Guillemot F (1996) Restricted expression of a novel murine atonal-related bHLH protein in undifferentiated neural precursors. Dev Biol 180:227-241.

Graham V, Khudyakov J, Ellis P, Pevny L (2003) SOX2 functions to maintain neural progenitor identity. Neuron 39:749-765.

Gray GE, Sanes JR (1991) Migratory paths and phenotypic choices of clonally related cells in the avian optic tectum. Neuron 6:211-225.

Greene LA, Angelstro JM (2008) Nerve growth factor gene regulated gene expression. In: Handbook of neurochemistry and molecular neurobiology: development and aging changes in the nervous system (Lajtha A, Perez-Polo JR, Rossner S, eds), pp 21-52. New York: Springer.

Greene LA, Tischler AS (1976) Establishment of a noradrenergic clonal line of rat adrenal pheochromocytoma cells which respond to nerve growth factor. Proc Natl Acad Sci U S A 73:2424-2428.

Groves AK, George KM, Tissier-Seta JP, Engel JD, Brunet JF, Anderson DJ (1995) Differential regulation of transcription factor gene expression and phenotypic markers in developing sympathetic neurons. Development 121:887-901.

Herberth B, Minkó K, Csillag A, Jaffredo T, Madarász E (2005) SCL, GATA-2 and Lmo2 expression in neurogenesis. Int J Dev Neurosci 23:449-463.

Holubec H, Payne CM, Bernstein H, Dvorakova K, Bernstein C, Waltmire CN, Warneke JA, Garewal H (2005) Assessment of apoptosis by immunohistochemical markers compared to cellular morphology in ex vivostressed colonic mucosa. J Histochem Cytochem 53:229-235.

Kala K, Haugas M, Lilleväli K, Guimera J, Wurst W, Salminen M, Partanen J (2009) Gata2 is a tissue-specific post-mitotic selector gene for midbrain GABAergic neurons. Development 136:253-262.

Kaneko Y, Sakakibara S, Imai T, Suzuki A, Nakamura Y, Sawamoto K, Ogawa Y, Toyama Y, Miyata T, Okano H (2000) Musashil: an evolutionally conserved marker for CNS progenitor cells including neural stem cells. Dev Neurosci 22:139-153.

Karunaratne A, Hargrave M, Poh A, Yamada T (2002) GATA proteins identify a novel ventral interneuron subclass in the developing chick spinal cord. Dev Biol 249:30-43.

Koga S, Yamaguchi N, Abe T, Minegishi M, Tsuchiya S, Yamamoto M, Minegishi N (2007) Cell-cycle-dependent oscillation of GATA2 expression in hematopoietic cells. Blood 109:4200-4208.

Kornhauser JM, Leonard MW, Yamamoto M, LaVail JH, Mayo KE, Engel JD (1994) Temporal and spatial changes in GATA transcription factor expression are coincident with development of the chicken optic tectum. Brain Res Mol Brain Res 23:100-110.

LaVail JH, Cowan WM (1971) The development of the chick optic tectum. II. Autoradiographic studies. Brain Res 28:421-441.

Lugus JJ, Chung YS, Mills JC, Kim SI, Grass J, Kyba M, Doherty JM, Bresnick $\mathrm{EH}$, Choi K (2007) GATA2 functions at multiple steps in hemangioblast development and differentiation. Development 134:393-405.

Lurie LJ, Boyer ME, Grass JA, Bresnick EH (2008) Differential GATA factor stabilities: implications for chromatin occupancy by structurally similar transcription factors. Biochemistry 47:859-869.

Minegishi N, Suzuki N, Kawatani Y, Shimizu R, Yamamoto M (2005) Rapid turnover of GATA-2 via ubiquitin-proteasome protein degradation pathway. Genes Cells 10:693-704.

Nakamura H (2001) Regionalisation and acquisition of polarity in the optic tectum. Prog Neurobiol 65:473-488.

Nardelli J, Thiesson D, Fujiwara Y, Tsai FY, Orkin SH (1999) Expression and genetic interaction of transcription factors GATA-2 and GATA-3 during development of the mouse central nervous system. Dev Biol 210:305-321.

Nozawa D, Suzuki N, Kobayashi-Osaki M, Pan X, Engel JD, Yamamoto M (2009) GATA2-dependent and region-specific regulation of Gata2 transcription in the mouse midbrain. Genes Cells 14:569-582.

O'Leary DD, McLaughlin T (2005) Mechanisms of retinotopic map development: Ephs, ephrins, and spontaneous correlated retinal activity. Prog Brain Res 147:43-65.

Osório J, Mueller T, Rétaux S, Vernier P, Wullimann MF (2010) Phylotypic expression of the bHLH genes Neurogenin2, Neurod, and Ascl1 in the mouse embryonic forebrain. J Comp Neurol 518:851-871.

Polanski W, Enzensperger C, Reichmann H, Gille G (2010) The exceptional properties of 9-methyl-beta-carboline: stimulation, protection and regeneration of dopaminergic neurons coupled with anti-inflammatory effects. J Neurochem 113:1659-1675.

Reeves FC, Burdge GC, Fredericks WJ, Rauscher FJ, Lillycrop KA (1999) Induction of antisense Pax-3 expression leads to the rapid morphological differentiation of neuronal cells and an altered response to the mitogenic growth factor bFGF. J Cell Sci 112:253-261.

Rodrigues NP, Janzen V, Forkert R, Dombkowski DM, Boyd AS, Orkin SH, Enver T, Vyas P, Scadden DT (2005) Haploinsufficiency of GATA-2 perturbs adult hematopoietic stem-cell homeostasis. Blood 106:477-484.

Sakakibara S, Nakamura Y, Yoshida T, Shibata S, Koike M, Takano H, Ueda S, 
Uchiyama Y, Noda T, Okano H (2002) RNA-binding protein Musashi family: roles for CNS stem cells and a subpopulation of ependymal cells revealed by targeted disruption and antisense ablation. Proc Natl Acad Sci U S A 99:15194-15199.

Scherzer CR, Grass JA, Liao Z, Pepivani I, Zheng B, Eklund AC, Ney PA, Ng J, McGoldrick M, Mollenhauer B, Bresnick EH, Schlossmacher MG (2008) GATA transcription factors directly regulate the Parkinson's diseaselinked gene $\alpha$-synuclein. Proc Natl Acad Sci U S A 105:10907-10912.

Shimizu R, Yamamoto M (2005) Gene expression regulation and domain function of hematopoietic GATA factors. Semin Cell Dev Biol 16:129-136.

Sugiyama S, Nakamura H (2003) The role of Grg4 in tectal laminar formation. Development 130:451-462.

Thompson J, Lovicu F, Ziman M (2004) The role of Pax7 in determining the cytoarchitecture of the superior colliculus. Dev Growth Differ 46:213218.

Thompson JA, Zembrzycki A, Mansouri A, Ziman M (2008) Pax7 is requisite for maintenance of a subpopulation of superior collicular neurons and shows a diverging expression pattern to Pax3 during superior collicular development. BMC Dev Biol 8:62.

Tong Q, Dalgin G, Xu H, Ting CN, Leiden JM, Hotamisligil GS (2000) Function of GATA transcription factors in preadipocyte-adipocyte transition. Science 290:134-138.

Tremblay P, Pituello F, Gruss P (1996) Inhibition of floor plate differentiation by Pax3: evidence from ectopic expression in transgenic mice. Development 122:2555-2567.
Tsai FY, Keller G, Kuo FC, Weiss M, Chen J, Rosenblatt M, Alt FW, Orkin SH (1994) An early haematopoietic defect in mice lacking the transcription factor GATA-2. Nature 371:221-226.

Tsarovina K, Pattyn A, Stubbusch J, Müller F, van der Wees J, Schneider C, Brunet JF, Rohrer H (2004) Essential role of Gata transcription factors in sympathetic neuron development. Development 131:4775-4786.

Tsarovina K, Reiff T, Stubbusch K, Kurek D, Grosveld FG, Parlato R, Schütz G, Rohrer H (2010) The GATA3 transcription factor is required for the survival of embryonic and adult sympathetic neurons. J Neurosci 30: 10833-10843.

van Eekelen JA, Bradley CK, Göthert JR, Robb L, Elefanty AG, Begley CG, Harvey AR (2003) Expression pattern of the stem cell leukaemia gene in the CNS of the embryonic and adult mouse. Neuroscience 122:421-436.

Wadman IA, Osada H, Grütz GG, Agulnick AD, Westphal H, Forster A, Rabbitts TH (1997) The LIM-only protein Lmo2 is a bridging molecule assembling an erythroid, DNA-binding complex which includes the TAL1, E47, GATA-1 and Ldb1/NLI proteins. EMBO J 16:3145-3157.

Wozniak RJ, Keles S, Lugus JJ, Young KH, Boyer ME, Tran TM, Choi K, Bresnick EH (2008) Molecular hallmarks of endogenous chromatin complexes containing master regulators of hematopoiesis. Mol Cell Biol 28:6681-6694.

Xu Z, Maroney AC, Dobrzanski P, Kukekov NV, Greene LA (2001) The MLK family mediates c-Jun N-terminal kinase activation in neuronal apoptosis. Mol Cell Biol 21:4713-4724.

Zhou Y, Yamamoto M, Engel JD (2000) GATA2 is required for the generation of V2 interneurons. Development 127:3829-3838. 